\title{
Effect of nurse directed rehabilitation programme on quality of life among patients with HIV attending care and support centers of Kottayam district, Kerala, South India
}

\author{
Lucyamma CV. ${ }^{1 *}$, Kiran N U. ${ }^{2}$, C Itticheriya C. ${ }^{3}$ \\ DOI: https://doi.org/10.17511/ijphr.2016.i3.06
}

1* Lucyamma CV, Ph.D Scholar, Nitte University, Mangalore, Karnataka, India.

2 Udaya Kiran N, Professor \& Head, Department of Community Medicine, KSHEMA, Nitte University, Mangalore, Karnataka, India.

3 Cherian C Itticheriya, Department of Medicine, Government Medical College, Kottayam, Kerala, India.

\begin{abstract}
Background: HIV has become a long-term condition, which not only affect the physical health, but also lead to psychological and social problems. Nurse directed rehabilitation programme may help people by improving their overall health and their ability to deal with stress. Objectives: To assess the pretest level of quality of life in both experimental and control group and to evaluate the effectiveness of nurse directed rehabilitation programme on quality of life. Methods: This is a randomized control study conducted at selected Care \& Support Centers under the Medical College ART unit of Kottayam District. Purposive sampling was done for selection of care \& support centers and simple random sampling for patients. $130 \mathrm{HIV}$ infected patients were selected for the study and randomly divided into 2 groups with Mean \pm SD age of $35.84 \pm 7.45$ years. Both groups were homogenous. Experimental group were given rehabilitation programme for 30 minutes 4 days / week for 6 months. QOL Scale (WHOQOLHIV-BREF) was used to assess quality of life and outcome of rehabilitation programme. Results: Findings show that there is mean quality of life (62.95) falls on the poor level among patient with HIV infection and $98 \%$ subjects experiences poor quality of life $\left(x^{2}=0.341\right)$. Paired difference and $t$ value proves that nurse directed rehabilitation programme highly significant in increasing quality of life $(p<0.001)$ when compared with control group. Conclusion: The practice of nurse directed rehabilitation programme is effective as an adjunct therapy in patients with HIV infection that significantly improves the quality of life.
\end{abstract}

Keywords: CSC centre, HIV patient, Nurse directed rehabilitaton programme, QOL, WHOQOLHIVBREF scale

Corresponding Author

Lucyamma CV, Ph.D Scholar, Nitte University, Mangalore, Karnataka, India.

Email: lucyclarefcc@gmail.com
How to Cite this Article

To Browse

Lucyamma CV, Kiran NU, Itticheriya CC. Effect of nurse directed rehabilitation programme on quality of life among patients with HIV attending care and support centers of Kottayam district, Kerala, South India. Public Health Rev Int J Public Health Res. 2016;3(3):125-130.

Available From

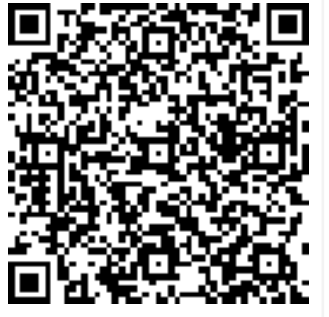

https://publichealth.medresearch.in/index.php/ijphr/ article/view/42
Manuscript Received 2016-05-24

Conflict of Interest No
Review Round 2 2016-06-15

Ethical Approval Yes
Review Round 3

Plagiarism X-checker $9 \%$
Accepted 2016-06-27

Note

(c) 2016 by Lucyamma CV, Udaya Kiran N, Cherian C Itticheriya and Published by Siddharth Health Research and Social Welfare Society. This is an Open Access article licensed under a Creative Commons Attribution 4.0 International License https://creativecommons.org/licenses/by/4.0/ unported [CC BY 4.0]. 


\section{Introduction}

Acquired Immunodefiency Syndrome (AIDS) is a highly, lethal, transmittable, syndrome which results from the infections of human immunodeficiency virus. The epidemic of HIV/AIDS enters into its fourth decade and is still considered an important public health problem in developed and developing countries [1]. With startling suddenness the HIV pandemic ripped surface veneer exposing the ugly realities, shortcomings, weaknesses and prejudices not only in the health system but in the entire social structure.

Worldwide, there are approximately 37 million people living with HIV/AIDS (UNAIDS2015). HIV is a leading cause of death worldwide. According to UN report (2015) India is a country with third largest number of people living with HIV. India has an estimated 2.39 million people living with HIV/AIDS [1]. The WHO estimates that $4.2 \%$ of adults aged 15-49 years are HIV positive in India. An increase in the number of HIV positive cases is noticed in Kerala; (2014) the last fiscal shows the highest increase of fresh HIV positive cases in the state [2].

HIV may have an impact on many life domains from the physical to the psychological social and vocational. HIV infection is multi-systemic [3]. It affects multiple body systems, including the musculoskeletal, neurological, and cardio respiratory systems.

HIV infection mainly affect on six major domains of quality of life (QOL), referred to as physical, psychological, level of independence, social, environmental and spiritual. The main symptoms reported by PLWHA include the OIs, night sweats, fatigue, weight loss, depression, anxiety; poor sleep quality and pain [3].

The experience of these symptoms negatively affects physical ability and consequently reduces quality of life, as patients experience limitations in their activities and participation. Participation in an exercise programme modifies the side effects of anti-retro viral therapy and quality of life may benefit [4].

Physical interventions, such as exercise, have been shown to be effective in improving physical function and psychological status for PLWHA. Patients with HIV infection are less involved in physical activity due to illness and are often not motivated to do exercise [5].
Nursing researches regarding exercise training in the management of HIV/AIDS are not conducted sufficiently in India, but some studies support that quality of life for the HIV patients can be improved significantly if proper rehabilitation is being done. Nurse directed rehabilitation programme is a package of physical exercises, physical and mental relaxation specially mentioned for patients with HIV infection.

\section{Aims and objectives}

01 . To assess pre test level of Quality of life of patients with HIV infection in experimental and control group.

02. To assess posttest level of Quality of life of patients with HIV infection in experimental and control group.

03. To evaluate the effectiveness of Nurse Directed Rehabilitation Programme (NDRP) on Quality of life of patients with HIV infection

Study design: Experimental design

\section{Methodology}

All 130 patients after baseline assessment were randomly allotted into two groups by using simple random sampling method. Quality of life was assessed by standardized tool like WHOQOLHIVBREF Scale [6]. The study was conducted at Care and Support (CSC) centers of Kottayam district, Kerala. A quantitative approach, experimental design was adopted for the study. Study was cleared by institutional ethical committee.

130 patients of both sexes, within the age range of 18-45 years with HIV infection with ART, willing to participated exercise programme, already not on consistent physical exercise, blood CD4 count between 300 to 600 and a regular visitor to the center were included for the study. Patients with mentally challenged/disturbed persons, medical contra indication to do the exercises and suffering from AIDS related illness and other inflammatory diseases were excluded.

All patients fulfilling selection criteria were provided informed consent for participating in the research. The Experimental Group was receiving individual teaching and demonstration of exercises and Control Group receiving no exercises. Each exercise sessions involved a warming up for 5 minutes with light stretching of muscles, joints and breathing exercise and followed by 30 minutes of physical 
Exercises and mental relaxation and cool down at the end for 5 minutes. Physical exercises include deep breathing, stretching activities for major muscle group and exercise for major joints, progressive muscle relaxation and mental relaxation. Duration of intervention was 4 days per week for 6 months and control group was advised not to do any exercise.

QOL was assessed by WHOQOLHIV-BREF Scale after 2nd and 6th months respectively for both experimental and control group. Data were analyzed using chi-square test, independent t-test and paired t-test. Statistical package for social sciences (SPSS 20.0) software was used for statistical analysis of data.

\section{Results}

Quality of life- In order to find the QOL, WHOQOLHIV-BREF scale was used. The final scores calculated under each domain were arbitrarily categorized as below:

01. 24-48 Poor QOL

02. 49-96 moderate QOL

03. 97-120 good QOL

There were 34 males and 31 females in experimental group and 30 males and 35 females in control group. The Mean \pm SD age of experimental Group is $36.96 \pm 5.94$ and Control Group is $34.72 \pm 8.61$ years.
Both groups were homogenous at base line and significant differences of post intervention data were analyzed by paired t-test.

Significant changes within group were analyzed with paired t test. The chi-square test for between group analyses at baseline for CD4 count shows $p$ value equal to 0.151 and the independent $t$ - test for $\mathrm{QOL}$ score shows $p$ value equal to 0.417 . These variables were proved homogeneous at baseline.

Pretest findings show that Quality of life was poor among $52.5 \%$ of subjects, $47.5 \%$ had moderate and no one experienced good quality of life. Table 1 shows mean QOL score was lowest in social domain

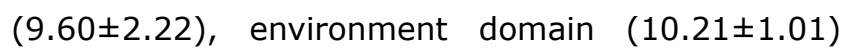
and spiritual domain $(8.10 \pm 1.91)$.

An overall significance level was maintained at $p$ value less than 0.05 . The Mean \pm SD at baseline for WHOQOLHIV-BREF Scale is $62.95 \pm 7.02$ and $71.72 \pm$ $6.10,80.35 \pm 7.10$ after intervention respectively with $p$ value equal to 0.001 shows significant improvement in quality of life of the subjects with HIV after the rehabilitation programme. These details were shown in Table-2 \& 3 .

Findings of the present study reveal that there is significant difference between mean pretest and post test QOL scores in experimental group. The $p$ value in experimental group in all domains shows changes in QOL and significant at $\mathrm{p}<0.001$ proves rehabilitation programme is effective in improving QOL in patients with HIV after 6 months.

Table-1: Quality of life among patients with HIV infection before intervention $(\mathbf{n}=130)$

\begin{tabular}{|l|l|l|l|l|l|l|l|}
\hline \multicolumn{2}{|c|}{} & \multicolumn{1}{|c|}{$\begin{array}{c}\text { Physical } \\
\text { Domain }\end{array}$} & \multicolumn{1}{|c|}{$\begin{array}{c}\text { Psychological } \\
\text { domain }\end{array}$} & $\begin{array}{c}\text { Level of Independence } \\
\text { domain }\end{array}$ & \multicolumn{1}{|c|}{$\begin{array}{c}\text { Social Relation } \\
\text { domain }\end{array}$} & \multicolumn{1}{|c|}{$\begin{array}{c}\text { Environment } \\
\text { domain }\end{array}$} & \multicolumn{1}{c}{$\begin{array}{c}\text { Spirituality } \\
\text { domain }\end{array}$} \\
\hline $\begin{array}{l}\text { Experimental } \\
\text { group }\end{array}$ & $\begin{array}{l}\text { Mean } \\
\text { SD }\end{array}$ & $11.06 \pm 1.97$ & $12.35 \pm 2.54$ & $11.82 \pm 1.76$ & $10.02 \pm 2.22$ & $10.21 \pm 1.01$ & $8.10 \pm 1.91$ \\
\cline { 3 - 9 } Control group & & $11.08 \pm 2.05$ & $10.75 \pm 1.47$ & $11.68 \pm 2.29$ & $9.60 \pm 2.21$ & $10.91 \pm 1.67$ & $9.15 \pm 1.79$ \\
\hline
\end{tabular}

Table-2: Effectiveness of NDRP on quality of life pre test and post test (experimental group) $(n=130)$

\begin{tabular}{|c|c|c|c|c|c|c|c|}
\hline \multicolumn{2}{|c|}{ Outcome measure } & \multirow[t]{2}{*}{ Mean } & \multirow[t]{2}{*}{ SD } & \multicolumn{2}{|c|}{ Paired differences } & \multirow[t]{2}{*}{$\mathbf{t}$} & \multirow[t]{2}{*}{$\mathbf{p}$} \\
\hline & & & & Mean & SD & & \\
\hline \multirow[t]{2}{*}{ WHOQOLHIV-BREF Scale } & Pretest Posttest after 2 month & 62.9571 .72 & 7.026 .10 & 8.76 & 6.95 & 10.17 & 0.001 \\
\hline & Pretest Post test after 6 month & 62.9580 .35 & 7.027 .10 & 17.40 & 8.84 & 15.85 & $.000 * *$ \\
\hline
\end{tabular}

$p<0.001$, Significant, $p=0.000 * *$, highly significant

Table 3: Effectiveness of NDRP on quality of life pre test and post test (control group) $(n=130)$

\begin{tabular}{|c|c|c|c|c|c|c|c|}
\hline \multicolumn{2}{|r|}{ Outcome measure } & \multirow[t]{2}{*}{ Mean } & \multirow[t]{2}{*}{ SD } & \multicolumn{2}{|c|}{ Paired differences } & \multirow[t]{2}{*}{$\mathbf{t}$} & \multirow[t]{2}{*}{ p } \\
\hline & & & & Mean & SD & & \\
\hline \multirow[t]{2}{*}{ WHOQOLHIV-BREF Scale } & Pretest Posttest after 2 month & 64.4264 .48 & 6.956 .66 & .062 & 9.45 & .052 & .958 \\
\hline & Posttest after 6 month Posttest after 6 month & 64.94 & 5.435 .43 & .523 .523 & 8.828 .82 & .478 .478 & .634 .634 \\
\hline
\end{tabular}


$P>0.05$, Not significant

\section{Discussion}

A number of published studies suggest and acknowledge that exercise is the best and effective therapeutic interventions for HIV/AIDS infected people to make their living qualitatively [7]. This is one of the interventional nursing studies done for Indian peoples with HIV/AIDS. Exercise group was advised to do their house hold work and duties and make them to understand the way of doing exercise in a regular time. Exercise training was given under supervision. Control group was advised not to do any exercises, but to carry on their activities of daily living and his /her occupation.

The present study finding reveals that QOL was poor among $52.5 \%$ of patients, $47.5 \%$ had moderate and no one experienced good quality of life. Mean QOL score was lowest in the social domain $(9.60 \pm 2.22)$, environment domain $(10.21 \pm 1.01)$ and spiritual domain ( $8.10 \pm 1.91)$. This reveals that patients with HIV face social, environment and spiritual (spirituality/religion and personal beliefs domain) problems than other ailments.

These findings supported by a descriptive crosssectional study conducted in Nigeria also revealed low QOL mean scores in the environment domain $(14.08 \pm 1.95)$ and social domain $(15.11 \pm 2.26)$ compared with other domains [8]. The present study contradict the findings that PLHIV receiving ART in Orissa had moderate QOL; scoring maximum in SRPB domain and lowest in social relationship. [9]

Findings of the present study reveal that there is significant difference between mean pretest $(62.95 \pm 7.02)$ and post test $(80.35 \pm 7.10)$ QOL scores in experimental group. The Mean \pm SD for $\mathrm{QOL}$ in patients with HIV is $62.95 \pm 7.02$ and $80.35 \pm 7.10$ before and after intervention respectively. The calculated $t$ value in experimental group in all domains showed changes in QOL and significant at $(p<0.001)$. Hence it is prove that statistically rehabilitation programme is effective to improve QOL in patients after 6 months.

The findings supported by an experimental study conducted in Chennai which showed that the Mean \pm SD for 3MST is $3.60 \pm 0.63$ and $4.33 \pm 0.72$ for before and after intervention respectively with $p$ value equal to 0.001 proves statistically significant improvement in cardiovascular fitness after Progressive Resistance exercises for 3 months [10].
The present study findings supported the results of the study conducted in ART center, District Hospital, Udupi. Thirty people living with HIV who were admitted were selected and different scales on anxiety and depression scale for people living with HIV were administered. Purposive sampling technique was used for the study.

Out of 30 subjects, $13.30 \%$ (4) experienced abnormal anxiety and $16.7 \%$ (5) abnormal depression. There was significance difference between mean difference of pretest and post test scores of anxiety $(t=8.471, d f=29, p=0.001)$ and depression $(t=6.811, d f=29, p=0.001)$.

Anxiety is independent of the selected variables (Demographic and disease specific). Depression is dependent on previous history of psychiatric illness $(\div 2=6.584$, df $=2, p=0.037)$. JPMR is a simple noninvasive, cost effective method. The result showed that JPMR training had a positive effect in reducing the anxiety and depression and JPMR can be used as an effective alternative therapy [11].

The study findings supported the results of the study conducted in Tokyo Metropolitan Komagome Hospital, examined the efficacy of relaxation techniques in a sample of HIV patients without AIDS in the early stages after infection, by comparing the three groups: relaxation group (progressive muscle relaxation and modified autogenic training); ordinary supportive psychotherapy group, and finally no psychiatric treatment group.

The sample selected were 19 people living with HIV. Scores for anxiety, fatigue, depression and contusion, as measured by the profile of mood states (POMS), were significantly lower after relaxation than before. There were no significant differences in the POMS scores (except for anger) among the three groups.

The results of patients using relaxation showed that difference between pre test and post test (mean $=38.7, \mathrm{SD}=7.8, P=<0.05)$. Results suggest that a combination of progressive muscle relaxation and modified autogenic training is a useful method, which can be easily employed in HIV patients without AIDS. [12]

The results of experimental group had shown that there was statistically significant difference in improvement in quality of life that was assessed by WHOQOL-HIV BREF scales. These results had been supported by many studies. 
In this study, individually the effects of rehabilitation programme is assessed and proved there was marked improvement in functional wellbeing and positive changes in quality of life.

Participation in an exercise programme modify the side effects of anti retro viral therapy and it is one key management to address impairment, activity limitation and participation restriction [10]. Four day weekly participation of Nurse directed rehabilitation programme for six months may be sufficient for improving the quality of life. The limitation in this study may be the long time follow up of patients reported chance of drop outs from study.

This study evaluated the effect of physical exercises and mental relaxation on health-related quality of life in HIV infected individuals. Six dimensions of health-related quality of life were evaluated. Overall health, which explores general health perceptions and feelings of well being were compared in both the groups.

This study led to the inference that Nurse directed rehabilitation programme can improve physical wellbeing and quality of life in HIV infected individuals. In summary, Nurse directed rehabilitation programme for six months suggested as an important component in the management of HIV infected individuals.

\section{Conclusion}

Nurse directed rehabilitation programme (4 days /week for 6 months of 30 minutes per session) improves quality of life and functional wellbeing of patients with HIV Infection.

\section{Disclosures}

This study is part of on-going PhD research titled "Effect of Nurse Directed Rehabilitation Programme among Patients with HIV and its Impact on Quality of Life (QOL) in Selected Community Art Centers of Kottayam District, Kerala State by first author. The study is cleared by Institutional Ethical Committee of Nitte University,NU/CEC/Ph.D-48/12 dated 16.1.2012 and registration number NU/PhD/AH/NSG/07/2011.

\section{Reference}

01. UNAIDS Report. How AIDS changed everything. July 2015.

Available from: [Article] [Crossref]
02. Ministry of Health and Family Welfare. HIV/AIDS wing; Kerala. Aug 2015.

Available from: [Article] [Crossref]

03. Mbada CE, Onayemi O, Ogunmoyole $Y$, Johnson $\mathrm{OE}$, Akosile CO. Health-related quality of life and physical functioning in people living with HIV/AIDSH. Qual Life Outco. 2013;11; 106-107. [Crossref]

04. Anandh V, D'sa IP, Alagesan J, Rathod V. Effect of Progressive Resistance exercises on cardio vascular fitness and quality of life in people with HIV/AIDS. J of Pharma and Bio Sci. $2011 ; 13(13) 19-22$.

Available from: [Article] [Crossref]

05. Ciccolo JT, Jowers EM, Bartholomew JB. The benefits of exercise training for quality of life in HIV/AIDS In the post-HAART. Era Sport Med. 2004;34(8)487-99.

[Crossref]

06. Mental Health. Evidence and Research, Department of Mental Health and Substance Dependence, World Health Organization. WHOQOL-HIV Instrument, Users ManualScoring and Coding for the WHOQOL HIV Instruments. Geneva- World Health Organization. 2002.

Available from: [Article] [Crossref]

07. Baigis J, Korniewicz DM, Chase G, Butz A, Jacobson D. Effectiveness of a home-based exercise intervention for HIV-infected adults- a randomized trial. J Assoc Nurses AIDS Care. 2002;13(2)33-45.

[Crossref]

08. Folasire OF, Irabor AE, Folasire AM. Quality of life of people living with HIV and AIDS attending the anti retro viral clinic, University College Hospital, Nigeria. Afr J Prim Health Care Fam Med. 2012;4(1)294-8.

[Crossref]

09. Anand D, Puri S, Mathew M. Assessment of Quality of Life of HIV-Positive People Receiving ART- An Indian Perspective Orissa, India. In J Com Med. 2012;37(3)165.

Available from: [Article] [Crossref] 
10. Anandh V, D'SA IP, Alagesan J, Rajendran K. Effect of Progressive Resistance Training on Functional Capacity, Quality of Life and CD4 Count in People with HIV/AIDS. Int J Physio Res. 2014;2(4)626-30.

Available from: [Article] [Crossref]

11. Bommareddi P, Prabha B, Valsaraj S. Jacobson's progressive muscle relaxation (JPMR) Training to reduce anxiety and depression among People living with HIV. NUJHS. 2014;4(1)71-78.

Available from: [Article] [Crossref]

12. Fukunishi I, Hosaka T, Matsumoto T, Hayashi M, Negishi M. Liaison Psychiatry and HIV InfectionApplication of Relaxation in HIV Positive Patients. Psy \& Clinl Neuro sci. 2005;50;305308.

[Crossref] 